\title{
EFEKTIVITAS PERLAKUAN PIJAT EFFLEURAGE PADA KALA I FASE AKTIF PERSALINAN UNTUK MENGURANGI RASA NYERI PADA IBU BERSALIN DI BPM YUSNAENI BULAN MEI TAHUN 2013
}

\author{
Iswari Paramita', Mustika Pramestyani ${ }^{2}$, Fisna Fitriannisa ${ }^{3}$ \\ ${ }^{1}$ Dinas Kesehatan Kota Yogyakarta, ${ }^{2}$ STIKes Guna Bangsa Yogyakarta, \\ ${ }^{3}$ STIKes Guna Bangsa Yogyakarta
}

\begin{abstract}
Background : At the first active phase is currently the most tiring and heavy. In this phase, most women feel intense pain due to uterine activity began to be more active. Increasing number of women who want to give birth with the birth process that takes place without pain cause a variety of methods are used to reduce pain in childbirth. The most frequently performed to reduce pain is to massage method. But sometimes the method of massage that is done not in place so that the result is inefficient.
\end{abstract}

Objectives : To examine the effectiveness of effleurage massage treatment at the first stage of the active phase of labor to reduce maternal pain in BPM Yusnaeni.

Methods : The study was a Quasi Experiment with One Group Pre-test Post-test. Respondents in this study were all mothers delivered at the first stage of the active phase in the BPM Yusnaeni by the number of study subjects were 10 mothers were taken by way of Non-Probability sampling technique with saturated.

Results : Statistical test Wilcoxon Signed Ranks Test showed $Z_{\text {test }}$ at $-2,873$ with $Z_{\text {staistic }}$ value for ( $p$ $<0.05$ ) is equal to -1.96 . From the results of calculations using the Wilcoxon Signed Ranks Test is also known that $Z_{\text {test }}>Z_{\text {statistic }}(-2,873>-1.96)$. It means that $H o$ is rejected or there is a difference of pain before and after the effleurage massage.

Conclusion: There is a massage treatment effectiveness eflleurage the first stage of labor to reduce maternal pain

Keywords : first active phase, back massage, pain intens.

\section{PENDAHULUAN}

Persalinan adalah proses pengeluaran hasil konsepsi yang dapat hidup dari uterus melalui vagina ke dunia luar. Proses persalinan dibagi menjadi empat kala, yaitu kala I, kala pembukaan servik atau jalan lahir, dimana servik membuka sampai terjadi pembukaan $10 \mathrm{~cm}$. Kala II disebut kala pengeluaran janin. Kala III disebut kala pelepasan dan pengeluaran plasenta. Kala IV observasi dini terhadap perdarahan postpartum (Wiknjosastro, 2005).

Intensitas dan lama kontraksi uterus pada fase aktif meningkat dan kontraksi terjadi lebih sering (setiap 3-5 menit). Dilatasi serviks mencapai 4-10 cm, secara umum merasakan peningkatan ketidaknyamanan dan nyeri mulai tidak dapat di kontrol, berkeringat, mual dan muntah, kemerahan, mengalami gemetar pada paha dan kaki, tekanan pada kandung kemih dan rektum, pucat sekitar mulut, berfokus pada diri sendiri mungkin lebih sensitif (Reeder,2011).

Menurut Danuatmaja dan Meiliasari (2008) saat yang paling melelahkan dan berat, dan kebanyakan ibu mulai merasakan sakit atau nyeri pada saat persalinan adalah kala I fase aktif. Dalam fase ini kebanyakan ibu merasakan sakit yang hebat karena kegiatan rahim mulai lebih aktif. Pada fase ini kontraksi semakin lama semakin kuat dan semakin sering.

Semakin banyaknya wanita yang ingin melahirkan dengan proses persalinan yang berlangsung tanpa rasa nyeri menyebabkan berbagai cara dilakukan untuk menurunkan nyeri pada persalinan, baik dengan teknik farmakologi maupun nonfarmakologi. Menurut Potter dan Perry (2005) tindakan peredaan nyeri persalinan secara nonfarmakologi antara lain dapat dilakukan dengan cara distraksi, biofeedback atau umpan balik hayati, hipnosis-diri, mengurangi persepsi nyeri, dan stimulasi kutaneus (massage, mandi air hangat, kompres panas atau dingin, stimulasi saraf elektrik transkutan).

Pijat diperkirakan bekerja dengan baik dalam memblokir impuls nyeri ke otak dan merangsang pelepasan endorfin lokal (hormon yang berguna untuk menurunkan nyeri). Dasar teori massage adalah teori gate control yang dikemukakan oleh Melzak dan Wall (1965). Kedua peneliti ini menemukan bahwa 
stimulasi ringan secara aktual dapat menghambat sensasi nyeri (Mander, 2003).

Penelitian yang dilakukan oleh Sylvia T (2001) menggunakan 10 metode nonfarmakologi yang dilakukan pada sampel 46 orang didapatkan bahwa teknik pernapasan, relaksasi, akupresur dan massage merupakan teknik yang paling efektif menurunkan nyeri saat persalinan (Arifin, 2008).

Nyeri pada persalinan merupakan masalah yang sangat mencemaskan bagi ibu bersalin, khususnya ibu primigravida, dan biasanya yang paling sering dilakukan untuk mengurangi rasa nyeri adalah dengan metode pijat, baik oleh petugas kesehatan, keluarga pasien ataupun pasien itu sendiri. Tetapi terkadang metode pijat yang dilakukan tidak pada tempatnya sehingga hasilnya tidak efisien. Salah satu cotohnya pada pelaksanaan teknik deep back massage, dimana seharusnya penekanan dilakukan tepat pada daerah sacrum dengan telapak tangan dan posisi ibu dalam keadaan berbaring miring tetapi kadang kala penatalaksanaan tidak sesuai sehingga nyeri yang dirasakan oleh pasien tidak berkurang. Hal ini mungkin diakibatkan oleh posisi ibu dalam keadaan berbaring miring, atau penekanannya tidak tepat pada daerah secrum. Hal ini tidak dilakukan satu kali saja tetapi harus berulang kali. Begitu juga dengan metode pijat yang lain. Selain alasan diatas, alasan lain peneliti mengambil judul ini adalah untuk mengurangi penggunaan metode farmakologi yang kurang ekonomis dan memiliki efek samping bagi ibu dan janin.

Survey pendahuluan peneliti pada 25 April 2013 di BPM Yusnaeni, di dapat pasien yang akan melakukan persalinan kala I fase aktif terlihat nampak cemas dan gelisah, karena tidak diberikan perlakuan pijat, dan di BPM tersebut belum pernah dilakukan penelitian tentang efektivitas perlakuan pijat effleurage tetapi sudah memberikan perlakuan pijat punggung. Untuk itu peneliti tertarik untuk meneliti efektivitas pengaruh pijat effleurage terhadap pengurangan rasa nyeri pada persalinan dengan melakukan salah satu metode pijat, sehingga peneliti mengambil judul "Efektivitas Perlakuan Pijat Effleurage Pada Kala 1 fase aktif Persalinan Untuk Mengurangi Rasa Nyeri Pada Ibu Bersalin Di BPM Yusnaeni Pada Bulan Mei Tahun 2013 “

\section{PEMBAHASAN}

1. Data variabel Karakteristik responden

a. Karakteristik responden berdasarkan Usia disajikan dalam bentuk distribusi frekuensi berdasarkan Usia responden di BPM Yusnaeni.

Tabel 1: Karakteristik responden berdasarkan Usia Di BPM Yusnaeni, Telukan Danurejo, Mertoyudan, Magelang

\begin{tabular}{llll}
\hline No & Usia & Frekuensi & $\begin{array}{l}\text { Presentase } \\
(\%)\end{array}$ \\
\hline 1. & $<20$ tahun & 2 & $20 \%$ \\
2. & $20-35$ tahun & 7 & $70 \%$ \\
3. & $>35$ tahun & 1 & $10 \%$ \\
& & & \\
\hline & Jumlah & 10 & $100 \%$
\end{tabular}

Sumber data : Data primer terolah, 2013

Berdasarkan Tabel 1 pada penelitian ini, rata-rata ibu melahirkan di BPM Yusnaeni berada pada rentang usia tidak berisiki yaitu 20-35 tahun. Presentase ibu dengan 20-35 tahun yaitu sebanyak 7 responden $(70 \%)$, responden yang berusia kurang dari 20 tahun sebanyak 2 responden (20\%), dan responden yang berusia lebih dari 35 tahun sebanyak 1 responden (10\%).

Penggolongan usia dilakukan peneliti berdasarkan tingkat risiko yang mungkin dialami ibu maupun janin. Usia muda cenderung dikaitkan dengan kondisi psikologis yang masih labil, yang memicu terjadinya kecemasan sehingga nyeri yang dirasakan menjadi lebih berat. Usia juga dipakai sebagai salah satu faktor dalam menentukan toleransi terhadap nyeri. Toleransi akan meningkat seiring bertambahnya usia dan pehaman terhadap nyeri. Hal ini sesuai dengan teori Yuliatun (2008) bahwa otak mengalami degenerasi seiring dengan pertambahan umur seseorang, sehingga orang yang lebih tua mempunyai ambang nyeri yang lebih rendah dan lebih banyak mengalami penurunan sensasi nyeri.

b. Karakteristik responden berdasarkan jumlah kehamilan disajikan dalam bentuk distribusi frekuensi berdasarkan jumlah kehamilan responden di BPM Yusnaeni.

Tabel 2: Karakteristik responden berdasarkan Jumlah Kehamilan Di BPM Yusnaeni, Telukan Danurejo, Mertoyudan, Magelang

\begin{tabular}{llll}
\hline No & $\begin{array}{l}\text { Jumlah } \\
\text { Kehamilan }\end{array}$ & Frekuensi & $\begin{array}{l}\text { Presentase } \\
(\%)\end{array}$ \\
\hline 1. & Primigravida & 4 & $40 \%$ \\
2. & Multigravida & 6 & $60 \%$ \\
\hline & Jumlah & 10 & $100 \%$ \\
\hline
\end{tabular}

Sumber data : Data primer terolah, 2013 
Berdasarkan tabel 2 pada penelitian ini didapatkan hasil dari 10 responden, primigravida sebanyak 4 responden $(40 \%)$, dan multigravida sebanyak 6 responden $(60 \%)$. Pada ibu primigravida umumnya merasa cemas dan takut menghadapi persalinan. Stres atau rasa takut ternyata secara fisiologis dapat menyebabkan kontraksi uterus menjadi terasa semakin nyeri dan sakit dirasakan. Ibu dalam kondisi inpartu tersebut mengalami stress maka tubuh merangsang tubuh mengeluarkan hormon stressor yaitu hormon Katekolamin dan hormon Adrenalin.

Katekolamin ini akan dilepaskan dalam konsentrasi tinggi saat persalinan jika ibu tidak bisa menghilangkan rasa takutnya sebelum melahirkan. Akibatnya tubuh tersebut maka uterus menjadi semakin tegang sehingga aliran darah dan oksigen ke dalam otot otot uterus berkurang karena arteri mengecil dan menyempit akibatnya adalah rasa nyeri yang tak terelakkan (Bobak. L, 2004). Sedangkan pada lbu multigravida sudah pernah melahirkan sehingga sudah punya pengalaman nyeri saat melahirkan. Ibu yang sudah mempunyai pengalaman melahirkan akan mampu merespon rasa nyeri tersebut. lbu yang melahirkan dalam keadaan rileks, semua lapisan otot dalam rahim akan bekerja sama secara harmonis sehingga persalinan akan berjalan lancar, mudah dan nyaman (Bobak. L, 2004).

c. Distribusi Frekuensi Karakteristik Responden Berdasarkan Tingkat nyeri sebelum dilakukan pijat effleurage.

Tabel 3 : Tingkat Nyeri Sebelum Diberi Perlakuan pijat effleurage $\mathrm{Di}$ BPM Yusnaeni, Telukan Tegalsari, Danurejo, Mertoyudan, Magelang

\begin{tabular}{llll}
\hline No. & Tingkat Nyeri & Frekuensi & Presentase (\%) \\
\hline 1. & Tidak Nyeri & 0 & 0 \\
2. & Nyeri Ringan & 0 & 0 \\
3. & Nyeri Sedang & 0 & 0 \\
4. & Menderita & 6 & $60 \%$ \\
5. & Sangat Menderita & 4 & $40 \%$ \\
6. & Menyiksa & 0 & 0 \\
\hline Jumlah & 10 & $100 \%$ \\
\hline \multicolumn{4}{c}{ Sumber data : Data primer terolah, 2013 }
\end{tabular}

Berdasarkan tabel 3 hasil penelitian diketahui bahwa nyeri persalinan sebelum dilakukan pijat effleurage dari 10 responden, sebanyak 6 responden (60\%) menunjukkan raut wajah menderita dan sebanyak 4 responden (40\%) menunjukkan raut wajah sangat menderita. Kecemasan seringkali menyertai nyeri. Hubungan antara kecemasan dan nyeri merupakan hubungan yang komplek, kecemasan seringkali meningkatkan respon nyeri, tetapi nyeri juga dapat menimbulkan kecemasan.

Kesehatan emosional seseoarang biasanya dapat mentoleransi lebih terhadap nyeri sedang bahkan nyeri berat dibandingkan dengan seseorang yang emosinya tidak stabil. Hal ini sesuai dengan teori Hartini (2005) Rasa takut dan cemas yang berlebihan akan mempengaruhi rasa nyeri. Setiap ibu mempunyai versi sendiri-sendiri tentang nyeri persalinan, karena ambang batas rangsang nyeri setiap orang berlainan dan subyektif sekali. Ada yang merasa tidak sakit hanya perutnya yang terasa kencang. Adapula yang merasa tidak tahan mengalami rasa nyeri. Beragam respon itu merupakan suatu mekanisme proteksi diri dari rasa nyeri yang dirasakan.

d. Distribusi Frekuensi karakteristik responden berdasarkan Tingkat Nyeri sesudah diberi perlakuan pijat effleurage.

Tabel 4: Tingkat Nyeri Sesudah Diberi Perlakuan pijat effleurage Di BPM Yusnaeni, Telukan Tegalsari, Danurejo, Mertoyudan, Magelang

\begin{tabular}{llll}
\hline No. & $\begin{array}{l}\text { Tingkat } \\
\text { Nyeri }\end{array}$ & Frekuensi & $\begin{array}{l}\text { Presentase } \\
(\%)\end{array}$ \\
\hline 1. & Tidak Nyeri & 0 & 0 \\
2. & $\begin{array}{l}\text { Nyeri } \\
\text { Ringan }\end{array}$ & 6 & $60 \%$ \\
3. & $\begin{array}{l}\text { Nyeri } \\
\text { Sedang }\end{array}$ & 4 & $40 \%$ \\
4. & Menderita & 0 & 0 \\
5. & $\begin{array}{l}\text { Sangat } \\
\text { Menderita }\end{array}$ & 0 & 0 \\
6. & Menyiksa & 0 & 0 \\
\hline & Jumlah & 10 & $100 \%$ \\
\hline
\end{tabular}

Sumber data : Data primer terolah, 2013

Berdasarkan tabel 4 menunjukkan bahwa dari 10 responden, sesudah dilakukan pijat effleurage sebanyak 6 responden $(60 \%)$ menunjukkan raut wajah Nyeri ringan, dan sebanyak 4 responden (40\%) menunjukkan raut wajah nyeri sedang. Dari hasil tersebut diketahui bahwa terdapat perbedaan Intensitas nyeri sebelum dan sesudah dilakukan pijat effleurage.

Hal ini juga menunjukkan bahwa terdapat penurunan intensitas nyeri setelah dilakukan pijat effleurage, meskipun intensitas penurunan nyeri tidak sama pada setiap individu. Penelitian yang dilakukan oleh Sylvia $\mathrm{T}$ (2001), menggunakan 10 metode nonfarmakologi yang dilakukan pada sampel 46 orang didapatkan bahwa teknik pernapasan, relaksasi, akupresur dan pijat merupakan teknik yang paling efektif 
menurunkan nyeri saat persalinan (Arifin, 2008)

Massage diperkirakan bekerja dengan baik dalam memblokir impuls nyeri ke otak dan merangsang pelepasan endorfin lokal (hormon yang berguna untuk menurunkan nyeri). Dasar teori massage adalah teori gate control yang dikemukakan oleh Melzak dan
Wall (1965). Kedua peneliti ini menemukan bahwa stimulasi ringan secara aktual dapat menghambat sensasi nyeri (Mander, 2003).

e. Hasil observasi Intensitas Nyeri sebelum dan sesudah dilakukan pijat effleurage.

Tabel 5 : Intensitas Nyeri sebelum dan sesudah pijat effleurage

\begin{tabular}{|l|l|l|l|}
\hline No. & R & Sebelum & Sesudah \\
\hline 1. & R 1 & Menderita & Nyeri ringan \\
2. & R 2 & Menderita & Nyeri ringan \\
3. & R 3 & Sangat menderita & Nyeri sedang \\
4. & R 4 & Menderita & Nyeri ringan \\
5. & R 5 & Menderita & Nyeri sedang \\
6. & R 6 & Menderita & Nyeri ringan \\
7. & R 7 & Menderita & Nyeri sedang \\
8. & R 8 & Sangat menderita & Nyeri ringan \\
9. & R 9 & Sangat menderita & Nyeri sedang \\
10. & R 10 & Sangat menderita & Nyeri ringan \\
& & & \\
\hline
\end{tabular}

Sumber data : Data primer terolah, 2013

Berdasarkan table 5 diketahui bahwa dari 10 responden sebelum dilakukan pijat effleurage sebanyak 6 responden menunjukkan raut wajah menderita dan sebanyak 4 responden menunjukkan raut wajah sangat menderita. Sedangkan sesudah dilakukan pijat effleurage dari 10 responden sebanyak 6 responden menunjukkan raut wajah Nyeri ringan, dan sebanyak 4 responden menunjukkan raut wajah nyeri sedang.

Melihat data tersebut diatas berdasarkan Intensitas nyeri sebelum dan sesudah dilakukan pijat tidak selalu berubah secara konstan, bisa dilihat dari data pada tabel.5 intensitas nyeri sebelum pijat pada tingkat menderita tidak selalu berubah menjadi nyeri ringan, bahkan ada yang hanya sampai tingkat nyeri sedang sesudah dilakukan pijat.

Demikian halnya dengan tingkat intensitas sangat menderita tidak selalu berubah menjadi ringan bahkan ada yang hanya sampai tingkat nyeri sedang sesudah dilakukan pijat. Efektivitas perlakuan pijat effleurage pada kala I fase aktif Persalinan Pada Ibu Bersalin untuk mengurangi rasa sakit di BPM Yusnaeni bulan Mei tahun 2013.

Berdasarkan Uji statistik Wilcoxon Signed Ranks Test menunjukkan Zhitung sebesar 2,873 dengan nilai $Z_{\text {tabel }}$ untuk ( $\alpha$ 5\%) adalah sebesar -1,96. Dari hasil perhitungan menggunakan Wilcoxon Signed Ranks Test tersebut juga diketahui bahwa $Z_{\text {hitung }}>Z_{\text {tabel }}$ ($2,873>-1,96$ ) sehingga dapat disimpulkan bahwa terdapat efektivitas perlakuan pijat effleurage pada kala I fase aktif persalinan untuk mengurangi rasa nyeri pada ibu bersalin di BPM Yusnaeni.

Penurunan nyeri yang terjadi karena pemberian pijat dengan teknik Effleurage pada area punggung menstimulasi serabut taktil kulit sehingga sinyal nyeri dapat dihambat dan korteks serebri tidak menerima sinyal nyeri tersebut, nyeri yang dirasakan pun dapat berkurang atau menurun. Menurut Danuatmaja dan Meliasari (2008) effleurage punggung selama 10-20 menit setiap jam dapat menurunkan tekanan darah, memperlambat denyut jantung, dan meningkatkan pernapasan.

Hal ini sesuai dengan teori Henderson (2006), massage punggung merupakan salah satu cara penanganan nyeri secara non farmakologis, Massage adalah memberikan tekanan tangan pada jaringan lunak biasanya otot, tendon atau ligamentum, tanpa menyebabkan gerakan atau perubahan posisi sendi untuk meredam nyeri, menghasilkan relaksasi dan memperbaiki sirkulasi. Massage dapat menghambat perjalanan rangsangan nyeri pada pusat yang lebih tinggi pada sistem syaraf pusat. Selanjutnya rangsangan taktil dan perasaan positif yang berkembang ketika dilakukan bentuk perhatian yang penuh sentuhan dan empati, bertindak memperkuat efek massage untuk mengendalikan nyeri.

Hasil penelitian ini juga didukung dengan penelitian yang pernah dilakukan oleh alifa (2008) tentang "Efek tekhnik massage Efflleurage pada abdomen terhadap penurunan intensitas nyeri pada disminore primer pada mahasiswa PSIK FKUB Malang". 
Dengan hasil bahwa tekhnik Effleurage terbukti dapat menurunkan intensitas nyeri disminore primer.

\section{KESIMPULAN}

Berdasarkan hasil penelitian yang dilakukan oleh penulis mengenai Efektivitas pijat effleurage pada kala I fase aktif persalinan untuk mengurangi rasa nyeri pada ibu bersalin di BPM Yusnaeni bulan Mei tahun 2013, maka penulis dapat menyimpulkan bahwa :

1. Karakteristik responden berdasarkan usia, sebagian besar berusia 20-35 tahun yaitu sebanyak $70 \%$.

2. Karakteristik responden berdasarkan jumlah kehamilan, sebagian besar multigravida, yaitu sebanyak $60 \%$.

3. Skala nyeri sebelum dilakukan pijat effleurage terbanyak adalah menderita, yaitu sebanyak $60 \%$.

4. Skala nyeri sesudah dilakukan pijat effleurage terbanyak adalah Nyeri ringan, yaitu sebanyak $60 \%$.

5. Berdasarkan Uji statistik Wilcoxon Signed Ranks Test menunjukkan Z Zitung sebesar $-2,873$ dengan nilai $Z_{\text {tabel }}$ untuk (a 5\%) adalah sebesar -1,96. Dari hasil perhitungan menggunakan Wilcoxon Signed Ranks Test tersebut juga diketahui bahwa $Z_{\text {hitung }}>Z_{\text {tabel }} \quad(-2,873>-$ 1,96) sehingga dapat disimpulkan bahwa terdapat efektivitas pijat effleurage pada kala I fase aktif persalinan untuk mengurangi rasa nyeri pada ibu bersalin di BPM Yusnaeni.

\section{SARAN}

1. Bagi ibu bersalin

Ibu bersalin perlu mempunyai motivasi tinggi untuk dapat mengelola kecemasan dengan cara mencari informasi tentang proses persalinan dan teratur melakukan antenal care. lbu bersalin juga disarankan untuk dapat membicarakan keluhan dan perasaan yang dialami kepada petugas kesehatan agar dapat dilakukan tindakan yang tepat untuk mengatasi keluhan tersebut.

2. Bagi bidan pelaksana

Bidan selalu mengajak pendamping/ suami/ keluarga untuk berperan aktif dalam mengurangi rasa nyeri selama kala I fase aktif dengan cara melatih pemijatan dengan tekhnik effleurage.

3. Bagi pendamping pendamping persalinan
Bagi pendamping/suami/keluarga agar berperan aktif untuk mengurangi rasa nyeri yang dialami ibu bersalin selama kala I fase aktif dengan melakukan pijat sesuai saran bidan.

4. Bagi peneliti selanjutnya

Bagi peneliti selanjutnya, penelitian ini dapat digunakan sebagai data dasar dan disarankan untuk membedakan dua kelompok yaitu klompok kontrol yang tidak diberikan perlakuan pijat effleurage dan kelompok perlakuan yang diberikan perlakuan pijat effleurage, agar dapat dinilai perbedaannya.

\section{DAFTAR PUSTAKA}

Alifa, (2008). Efek tekhnik massage Effleurage pada abdomen terhadap penurunan intensitas nyeri pada disminore primer pada mahasiswa PSIK FKUB Malang.

Andriana, E. (2007). Melahirkan tanpa rasa sakit. Jakarta : Bhuana Ilmu Populer.

Arikunto, (2010). Prosedur Penelitian : Suatu Pendekatan Praktek. Jakarta : Rineka Cipta

Bare, B.G., dan Smeltzer, S.C. (2002). Buku Ajar Keperawatan Medikal Bedah. Volume 2. Edisi 8. Jakarta : EGC

Bobak, L. (2005). Buku Ajar Keperawatan Maternitas edisi 4. Jakarta : EGC

Danuatmaja, B. \& Meiliasari, M. (2002) Persalinan Normal tanpa rasa sakit, puspa sehat, Jakarta: Puspa Swarna

Danuatmaja, B. (2004). Persalinan Normal Tanpa Rasa Sakit. Jakarta: Puspa Swarna.

Danuatmaja, B. dan Meiliasari, M. (2008). Persalinan Normal Tanpa Rasa Sakit. Jakarta: Puspa Swarna.

Fraser, D. M., dan Cooper, M. A. (2009). Buku Ajar Bidan Myles. Ed-14. Jakarta: EGC

Gadysa, G. (2009). Persepsi Ibu Tentang Metode Masase. Diambil 27 Februari2010, dari http://luluvikar.wordpress.com

Henderson, C. \& Kathleen, J. (2006). Buku Ajar Konsep Kebidanan. Jakarta: EGC.

Hidayat, A. (2007). Metode Penelitian Keperawatan dan teknik Analisis Data. Jakarta : Salemba Medika. 
Hidayat, A. (2008). Pengantar Kebutuhan Dasar Manusia. Jakarta : Salemba Medika.

Mander, R. (2003). Nyeri Persalinan. Jakarta : EGC.

Notoatmojo,s. 2010. Ilmu Perilaku Kesehatan. Jakarta : PT Rineka Cipta

Potter, P. A., dan Perry, A. G. (2005). Fundamental Keperawatan. Jakarta : EGC

Reeder, S.J, Martin, L.L, Kaniak D. (2011). Keperawatan Maternitas: Kesehatan Wanita, Bayi dan Keluarga. Alih bahasa Yati Afiyati, dkk. Edisi 18. Jakarta : EGC

Riwidikdo. (2007). Metodelogi Penelitian Kesehatan. Jakarta. Bina Pustaka.

Simkin, P., Whalley, J., dan Keppler, A. (2007). Panduan Lengkap Kehamilan, Melahirkan dan Bayi. Jakarta : Arcan.

Smeltzer. S.C, Bare. B. G. (2002). Buku Aajar Medikal Bedah. Volome 2. Edisi 8. Jakarta: EGC

Sugiyono, (2005). Memahami Penelitian Kualitatif. Bandung : Alfabeta
Sugiyono, (2006). Statistika Untuk Penelitian. Bandung : Alfabeta

Sugiyono, (2009). Metode Penelitian Bisnis. Bandung : Alfabeta

Sugiyono, (2010). Metode Penelitian Kuantitatif Kualitatif dan R\&D. Bandung: Alfabeta

Tamsuri, A. (2007). Konsep dan penatalaksanaan nyeri. Jakarta: EGC

Wibowo S. (2003). Farmakoterapi Nyeri Punggung Bawah. Dalam: Meliala L, Nyeri Punggung Bawah. Jakarta: Kelompok Studi Nyeri Perhimpunan Dokter Spesialis Saraf Indonesia

Wiknjosastro, H. (2005). Ilmu Kebidanan. Jakarta: Yayasan Bina Pustaka Sarwono Prawirohardjo

Winkjosastro, H. (2008). IImu Kebidanan. Jakarta : Yayasan Bina Pustaka Sarwono Prawiroharjo

Yuliatun, L. (2008). Penangangan Nyeri Persalinan Dengan Metode Nonfarmakologi. Malang: Bayumedia Publishing. 